\title{
1 Correlates of fatality risk of vulnerable road users in Delhi
}

\section{Rahul Goel ${ }^{1}$, Parth Jain ${ }^{2}$, Geetam Tiwari ${ }^{3}$}

$3 \quad{ }^{1}$ MRC Epidemiology Unit, University of Cambridge, United Kingdom

$4 \quad{ }^{2}$ Civil Engineering, Shiv Nadar University, Gautam Budh Nagar District, India

${ }^{3}$ Transportation Research and Injury Prevention Programme (TRIPP), Indian Institute of Technology Delhi, New Delhi, India

\begin{abstract}
Pedestrians, cyclists, and users of motorised two-wheelers account for more than $85 \%$ of all the road fatality victims in Delhi. The three categories are often referred to as vulnerable road users (VRUs). Using Bayesian hierarchical approach with a Poisson-lognormal regression model, we present spatial analysis of road fatalities of VRUs with wards as areal units. The model accounts for spatially uncorrelated as well as correlated error. The explanatory variables include demographic factors, traffic characteristics, as well as built environment features. We found that fatality risk has a negative association with socio-economic status (literacy rate), population density, and number of roundabouts, and has a positive association with percentage of population as workers, number of bus stops, number of flyovers (grade separators), and vehicle kilometers travelled. The negative effect of roundabouts, though statistically insignificant, is in accordance with their speed calming effects for which they have been used to replace signalised junctions in various parts of the world. Fatality risk is $80 \%$ higher at the density of 50 persons per hectare (pph) than at overall city-wide density of $250 \mathrm{pph}$. The presence of a flyover increases the relative risk by $15 \%$ compared to no flyover. Future studies should investigate the causal mechanism through which denser neighborhoods become safer. Given the risk posed by flyovers, their use as congestion mitigation measure should be discontinued within urban areas.
\end{abstract}

\section{Introduction}

Indian cities have witnessed an exponential growth of vehicles during the previous two decades or so, contributed largely by motorised two-wheelers (MTW) (Pucher et al., 2007; MoRTH, 2012). Coincident to this, burden from road traffic injuries in India has also been rising, and the number of deaths have more than doubled from 1991 through 2011 (Mohan et al., 2015). According to the official sources, there were more than 140,000 road deaths in year 2013-14 (NCRB, 2015). When expressed as the number of road deaths per 100,000 persons, fatality risk in India is 2 to 4 times higher than high-income settings such as the UK, Germany, France and Canada (MoRTH, 2012).

A majority of the victims are men in age-group 15-59 years (Gururaj, 2008; Mohan et al., 2009; Hsiao et al., 2013). Pedestrians, cyclists, and MTW riders have the largest share. The three road-user categories, with no rigid barrier protecting them against traumatic forces, are often termed as vulnerable road users (VRU) (Peden et al., 2004). Globally, VRUs account for around $46 \%$ of all road deaths (WHO, 2015), while in India this share is much higher.

According to Million Death Study, a national-level mortality survey in India, VRUs accounted for $68 \%$ of all road deaths during the period 2001-2003 (Hsiao et al., 2013). A study conducted in six Indian cities with 
population ranging between 1 to 2 million reported that the proportion of VRU fatalities for years 2008 through 2011 varied from $84 \%$ to $93 \%$ (Mohan et al., 2016). This proportion is much lower in high-income countries and is as low as $22 \%$ in the Americas (WHO, 2015). There are multiple factors contributing to these differences, such as road design, provision of safe infrastructure for pedestrians and cyclists, traffic management, and the enforcement of speed and alcohol limits. Apart from these, the major underlying difference is how people travel in these settings.

According to Census 2011, close to one-third of the workers (30\%) in Indian cities walk to work, $17 \%$ cycle, a quarter (25\%) use some form of public transport (bus, autorickshaw or train), more than one-fifth (22\%) use MTW and only 5\% use cars (Census-India, 2016). As a result, $69 \%$ of the workers can be categorised as VRUs during their commute trips. If we consider walking involved in either ends of a public transport trip, the proportion of work trips involving VRU reach up to $94 \%$.

When trips of all purposes are considered, data from various cities in India show that the share of nonmotorised modes is even higher (Arora et al., 2014; RITES, 2008; Goel, 2017). As a result, a large proportion of road users are exposed to high injury risk through collisions with high-powered motorised vehicles such as cars, buses, and trucks. This is in complete contrast with high-income settings where a large proportion of trips are carried out in cars. For instance, $86 \%$ of the work trips in the US (2009; McKenzie and Rapino, 2011), 64\% in the UK (2011; Gower, 2013) and 62\% in the Netherlands (2007; MOT, 2009) were carried out using cars. As a result, in case of a crash, the road users in these settings have much higher protection.

Road transport in India also differs in the form of motorisation from their western counterparts. Increasing motorisation is not resulting in reduction of VRUs on roads, as MTW remains a preferred mode of private transport. While MTW in India account for more than two-thirds of private motorised fleet (MoRTH, 2012), their share in western settings such as the USA, UK, Germany and France, is only 3-10\% (EEA, 2003; USDOT, 2015).

A large number of crash-level epidemiological studies have been carried out in India to understand the causal mechanism of crashes or the injury severity (Garg and Hyder, 2006). However, epidemiology of crashes using ecological models is lacking. In this study, we present a spatial analysis of VRU fatalities in Delhi to assess their geographic variation with respect to built environment, demographic factors, and traffic characteristics. We restricted our analysis to fatal crashes as number of injury crashes reported by police are highly underreported in India (Gururaja, 2006; Mohan et al., 2009; Mohan et al., 2015). Delhi being the capital of India and the seat of federal government has an active police department and is a dense urban area. Therefore, underreporting of traffic deaths in a setting like Delhi is highly unlikely.

\section{Literature Review}

Crash rates have been established to have a positive association with the speed of vehicles (Nilsson, 1981; Cameron and Elvik, 2010). In addition to the probability of a crash, speed of vehicles is also a determinant of severity level of injuries (OECD/ECMT, 2006; Aarts and Van Schagen, 2006). How fast vehicles travel on road is a function of built environment (Ewing and Dumbaugh, 2009) and road design features (Torok, 
conditions (Torok, 2011). Given these links of crashes with speed and that of speed with built environment, many studies have found association between crash rates and built environment (Ewing et al., 2003).

There are other factors which result in higher number of crashes such as through increasing the exposure to risk, increasing the chances of a crash, or increasing the severity of injury. Higher exposure to risk is a function of economic and demographic factors and mode of travel. Higher crash occurrence is associated with lack of law enforcement by police and lack of safe infrastructure for pedestrians and cyclists, and higher severity level can result from lack of forgiving vehicle front to protect pedestrians in a collision, use of seat belts by cars occupants and helmets by MTW riders and cyclists (Peden et al., 2004).

A large number of studies have carried out area-level crash modelling to quantify the association of road traffic injuries with built environment and traffic characteristics as well as population characteristics. Such models, after accounting for confounding variables, estimate the independent effects of different built environment variables, such as, type of junctions, intersection density, type of roads, speed limit, road widths, and road curvature. With this knowledge, built environment can be modified in ways which can increase the safety of road users. The sensitivity of safety to those modifications is given by the coefficients of the regression models.

Most of the area-level modelling studies have been carried out in settings from highly motorised developed countries-US, Canada, UK, and Australia. For instance, studies from cities/states in the US include San Francisco, California (LaScala et al., 2000; Wier et al., 2009), Tucson, Arizona (Guevara et al., 2004), Pennsylvania (Aguero-Valverde and Jovanis, 2006), Hawaii (Kim et al., 2006), Charlotte, North Carolina (Pulugurtha et al., 2006), California (Chakravarty et al., 2010), San Antonio, Texas (Dumbaugh et al., 2013), New York city (DiMaggio et al., 2015), Manhattan (Narayanmoorthy et al., 2013), New Jersey (Demiroluk and Ozbay, 2014), and Hillsborough and Pinellas counties of Florida (Siddiqui et al., 2012; Xu et al., 2017), from those in Canada include Toronto (Hadayeghi et al., 2003), Greater Vancouver region (Lovegrove and Sayed, 2006) and British Columbia (MacNab, 2004), those in UK, London (Quddus, 2008), England (Graham and Glaister, 2003; Noland and Quddus, 2004), and England and Wales (Jones et al., 2008), and in Australia, Melbourne (Amoh-Gyimah et al., 2016). Among low-and middle-income countries (LMICs), the only study reported is by Wang et al. (2016) in which they modeled pedestrian crashes in Shanghai city.

The areal unit of analyses used by various studies also varied and included counties (Aguero-Valverde and Jovanis, 2006; Demiroluk and Ozbay, 2014), census tracts (LaScala et al., 2000; Chakravarty et al., 2010; Narayanmoorthy et al., 2013; DiMaggio et al., 2015), census statistical area levels (Amoh-Gyimah et al., 2016), wards (Graham and Glaister, 2003; Noland and Quddus, 2004; Quddus, 2008), traffic analysis zones (TAZ) (Hadayeghi et al., 2003; Pulugurtha et al., 2013; Siddiqui et al., 2012; Wang et al., 2016; Xu et al., 2017), city blocks (Dumbaugh et al., 2013) or grids (Kim et al., 2006).

The modeling has been carried out using non-spatial models (Hadayeghi et al., 2003; Graham and Glaister, 2003; Noland and Quddus, 2004; Kim et al., 2006; Pulugurtha et al., 2013; Lovegrove and Sayed, 2006; Wier et al., 2009; Chakravarty et al., 2010; Dumbaugh et al., 2013), spatial models (LaScala et al., 2000; Macnab, 2004; Narayanmoorthy et al., 2013; Demiroluk and Ozbay, 2014; DiMaggio et al., 2015; Wang et al., 2016), as well as both (Quddus, 2008; Aguero-Valverde and Jovanis, 2006; Siddiqui et al., 2012; Amoh-Gyimah et al., 2016; Xu et al., 2017). Spatial models have accounted for spatial correlation using traditional econometric models, such as spatial autoregressive models (Quddus, 2008; LaScala et 
al., 2000) or spatial error models (Quddus, 2008) or using more recently developed hierarchical Bayesian modelling which include specifications of error terms for uncorrelated heterogeneity as well as spatial heterogeneity (Macnab, 2004; Aguero-Valverde and Jovanis, 2006; Quddus, 2008; Siddiqui et al., 2012; Wang et al., 2016; Amoh-Gyimah et al., 2016; Xu et al., 2017).

It is noteworthy that even though a major share of global road traffic injury burden is contributed by LMICs, their representation in such studies is almost absent. In Indian cities, most roads do not have posted speed limits, and when they do, police rarely enforces those. As a result, speed chosen by drivers is likely to be much more associated with traffic conditions, road design features and other built environment factors. This underscores the importance of built environment as risk factor for crashes in Indian cities. Other factors which set Indian cities apart from their high-income counterparts are lack of safe infrastructure for non-motorised modes, heterogeneous mix of traffic, low level of car-based travel and a high share of MTW. The contrasting contexts of on-road traffic mix, built environment, demographics, and level of traffic enforcement between India and high-income countries warrant an arealevel crash study in an Indian city.

\section{Case study city-Delhi}

Delhi is the capital city of India and one of the most heavily motorised large cities in India. Among the cities with population more than 10 million, it has the highest ownership of cars, with more than one in every 5 households owning a car (Guttikunda et al., 2014). Delhi along with its contiguous cities have grown rapidly over the last two decades. The population of the region more than doubled from 10 million in 1991 to 22 million in 2011, with Delhi contributing 16.7 million to the latter. Over the same period, the number of registered vehicles have increased by more than $300 \%$. Public transport (PT) is served through a combination of road- and rail-based modes. These include buses, intermediate public transportation such as cycle rickshaws, electric rickshaws, auto rickshaws or tuktuks, and mini buses, and rail-based systems including metro rail and commuter rail (Goel and Guttikunda, 2015; Goel and Tiwari, 2015).

According to Census 2011, among all the work trips in Delhi, up to a quarter of trips are walked (26\%), one-tenth are cycled (11\%), one-third use some form of public transport (32\%), 17\% use MTW and $13 \%$ use cars (Census-India, 2016). A large number of grade-separated intersections have been built in Delhi as a measure to reduce congestion as well as to reduce vehicular idling. Cycle lanes have been built as a part of 5.8-km long bus rapid transit corridor, while almost no other road in Delhi has cycle lanes. Though small isolated sections of cycle lanes have been built in various parts of the city. There is no helmet use among bicycle users in Delhi.

\section{Data}

In this study we model road deaths corresponding to the 3-year period: 2010 to 2012. The year 2011 corresponds to the latest Census. The inclusion of fatalities for three years brings stability in the fatality counts for disaggregated spatial units within the city. We used case-specific fatal crashes reported in First Information Reports (FIRs) compiled by Delhi Traffic Police for the years 2010 through 2012. FIRs are the first set of information documented by police department as reported by those involved in the crash or anyone who knows about the crash or by a police official (Mohan et al., 2015). 
The case-specific details consist of date, time, location, police station of the crash location, striking vehicle type, and victim road-user type. Age and gender of crash victims were available for year 2010 only. The three-year period includes a total of 5972 fatalities, which amounts to 1991 fatalities per year, and 11.9 fatalities per 100,000 persons, assuming 2011 census population as average of the 3-year period. In comparison, New York has a fatality rate of 3 per 100,000 persons (NYDMV, 2014), Greater London, 1.6, (TFL, 2014), and Amsterdam, 2 (iamsterdam, 2014). The three VRU categories, pedestrians (45.5\%), cyclists (5.9\%), and motorised two-wheeler (MTW) riders (34.5\%), contribute $86 \%(5138)$ of all the fatalities.

The location of the crashes mentioned in the FIR data consisted of the name of the road where the crash occurred along with a landmark. Using this information, geographical coordinates of the crash locations were identified using Google Maps as well as Wikimapia (http://wikimapia.org/country/India/Delhi/). The latter has information regarding informal landmarks known among local population and collected through crowdsourcing, which are often missing in Google Maps. In addition, we referred to jurisdiction map of police stations. Landmarks of some of the crash locations were reported using serial number of pillars of elevated metro corridors, and were also not available on Wikimapia. For these, we visited those road sections and geo-located those pillars using GPS.

We use wards as areal units which are administrative units in the city for the purpose of municipal corporations. In 2011, Delhi was divided in to 282 wards with an average size of $4.9 \mathrm{~km}^{2}$ with more than half (54\%) of all the wards having an area of less than $2 \mathrm{~km}^{2}$. The average number of VRU fatalities across the wards is 18 varying from a minimum of zero to maximum of 183 . We used ward-specific demographic and socio-economic statistics from Primary Census Abstract (PCA) reported by Census 2011.

From PCA, we used population, literacy rate, and percent of population who are workers. The population of wards also vary from $\sim 14,000$ to $\sim 146,000$ with an average of $\sim 58,000$. Literacy rate is defined as the percentage of population above 6 years who are literate. Workers have been classified based on the length of employment during the past one year-main worker: 6 months or more, marginal worker: less than 6 months, and non-worker: no employment. For our analysis, we only used the main worker category.

In the absence of city-wide traffic counts, modelled vehicle kilometers travelled (VKT) were used from Travel Demand Forecast Study (TDFS) commissioned by Transport Department of Delhi (RITES, 2008). The study carried out traffic assignment model for 2007 which consisted of volume of vehicles in each link (road segments), expressed as Passenger Car Units. TDFS also included validation of assignment model with the observed traffic counts at various locations. We used model output for 2007 and estimated wardspecific VKT using the sum total of product of length of each link and its corresponding volume. While the traffic deaths in our model refer to 2010-2012 period, we assume that 2007 traffic volume is sufficient for assessing relative variation across the wards. Even if the growth in traffic volume occurred, we assume that growth rate was consistent across the wards. 
ward. This was then multiplied by 3 since the fatality counts correspond to a three-year period. Thus, exposure accounts for population residing in the ward as well those visiting the ward during the course of a day. For instance, in case of a ward with offices and other commercial land use, while the residing population could be small, it will still attract a large number of people during the day. For estimating the number of external trips to wards we used TDFS study.

From TDFS, origin-destination (OD) matrices of person trips estimated for year 2011 were available for motorised modes and classified among four categories-car, MTW, intermediate public transport (IPT) which includes auto rickshaws (or tuk-tuks), and public transport (PT) including bus and train. We used OD matrices for year 2011 as these need to be consistent with the population which corresponds to 2011. We used sum total of all modes to estimate total trips destined to each zone. The OD units in TDFS are traffic analysis zones (TAZs) which were formed using wards. In cases where ward size was much bigger, TAZs were formed by dividing the ward into two or more units. By overlaying the TAZ over wards in a GIS platform, TAZs were mapped to their corresponding wards. Using this correspondence, ward-specific VKT and exposure were calculated using zonal data. The total number of external trips to each ward are shown in Table 1 as Person trips destined to ward.

Table 1: Descriptive statistics

\begin{tabular}{|c|c|c|c|c|c|}
\hline & Mean & Standard Deviation & Min & Median & Max \\
\hline Population & 58,046 & 19,205 & 14,217 & 54,404 & 145,715 \\
\hline Population Density & 49,359 & 38,216 & 1808 & 40,796 & 279,200 \\
\hline Person trips destined to ward & 38,786 & 31,192 & 5287 & 30,450 & 300,213 \\
\hline VKT & 2581 & 3396 & 20 & 1631 & 36,326 \\
\hline \# Bus stops & 12 & 13 & 0 & 9 & 67 \\
\hline \# Flyovers & 0 & 1 & 0 & 0 & 7 \\
\hline \# Roundabouts & 0 & 1 & 0 & 0 & 12 \\
\hline Area & 4.9 & 10.7 & 0.3 & 1.9 & 80.0 \\
\hline \# VRU fatalities & 18 & 20 & 0 & 13 & 183 \\
\hline \% Population main workers & 32.3 & 4.0 & 23.7 & 32.3 & 46.1 \\
\hline$\%$ Population (>6 years) literate & 86.6 & 5.5 & 72.0 & 87.5 & 97.1 \\
\hline
\end{tabular}

For built environment variables we included grade separators (overpass/flyovers), roundabouts, bus stops, and built-up population density. Built up area was identified using Google Earth for 2013 (Goel and Guttikunda, 2015), using which ward-specific population density were estimated. The average built-up population density of wards is 490 persons per hectare (pph), with $60 \%$ of the wards within 500 pph and $85 \%$ within $800 \mathrm{pph}$. Other built environment variables were also identified using Google Earth for year 2012. In case of grade-separated intersections, we used the corresponding intersection as a point location to represent grade separator. Most flyovers in Delhi connect two parallel legs of a major intersection to facilitate the uninterrupted movement of through moving traffic. Few flyovers span across more than one intersection and are often referred to as elevated roads. For those flyovers, we denoted locations at their beginnings and at their ends. Table 1 presents descriptive statistics of all the variables.

\section{Method}

The objective of this study is to explore the effect of built environment and demographic and socioeconomic characteristics of the population on the fatality risk of VRUs. For this, we used the Bayesian hierarchical modelling framework as proposed by Besag, York and Mollié (BYM) (Besag et al., 1991). The 
model has been implemented widely such as for cancer mapping by Cramb et al. (2011) and injury modelling by Quddus (2008) and Dimaggio et al. (2015). The model is described as follows:

$$
\begin{gathered}
y_{i}=\text { Poisson }\left(\theta_{i}\right) \\
\log \left(\theta_{i}\right)=\log \left(e_{i}\right)+\beta_{0}+\beta_{i} \mathrm{X}_{i}+\delta_{i}+v_{i}
\end{gathered}
$$

where, $y_{i}$ are the observed VRU fatality counts in each ward $i, \theta_{i}$ are the expected count of fatalities, $\mathrm{X}_{i}$ represents a vector of explanatory variables, or covariates for each ward, $e_{i}$ is the exposure, $\beta_{0}$ is the intercept, $\beta$ is a vector of fixed effect parameters, $\delta_{i}$ is the uncorrelated heterogeneity or unstructured error, and $v_{i}$ is the spatially correlated heterogeneity. The random error components represent the effects of unmeasured/unknown risk factors. Here, $\delta_{i}$ represents overdispersion and accounts for variation in the expected fatality risk of wards after controlling for the independent variables, and $v_{i}$ represents spatial patterns affecting fatality risk and not accounted for by the independent variables.

The first level of the hierarchical modeling framework presented in the equation (1) represents ward-level observed crash counts $\left(\mathrm{y}_{i}\right)$ generated from a Poisson distribution with an expected count of $\theta_{i}$. The second level, presented in equation (2), includes the linear relationship between log of expected counts and independent variables. Here, exposure $\left(e_{i}\right)$ is an offset (a covariate with coefficient value 1 ) and, therefore, effectively acts as a denominator for left-hand side of the equation. This in turn expresses the dependent variables as risk $\left(\log \left(\lambda_{i}\right)=\log \left(\theta_{i} / e_{i}\right)\right)$. Therefore, this modelling framework accounts for exposed population explicitly, rather than treating it as a covariate. Note that exposure is the sum total of population and the number of external trips destined to the ward.

The Bayesian modelling was done using R-INLA (Rue et al., 2009) which is an R package and employs Integrated Nested Laplace Approximations to estimate the posterior distributions. R-INLA has been recently developed as a computationally efficient alternative to Monte Carlo Markov Chain (MCMC). Unlike MCMC methods which rely on simulation methods to trace posterior distribution, INLA estimates parameters using a closed-form deterministic method and is much faster. It has been applied in injury modeling by Dimaggio et al. (2015).

R-INLA includes a latent model for uncorrelated random effects $\left(\delta_{i}\right)$, in which these effects are modelled as $\delta_{i} \sim N\left(0,1 / \tau_{\delta}\right)$, where $\tau_{\delta}$ refers to the precision of the Normal distribution and is inverse of the variance. $\log \left(\tau_{\delta}\right)$ is assigned a prior of log-gamma distribution with mean and precision of 1 and 0.0005 , respectively. Using $\log \left(\tau_{\delta}\right)$ instead of simply $\tau_{\delta}$ provides some advantages as $\log \left(\tau_{\delta}\right)$ is not constrained to be positive. Fixed effects, including the intercept, have a Gaussian prior with fixed mean and precision $(N(0,0.001))$.

For spatial dependence we use the intrinsic conditional autoregressive (CAR) specification as proposed by Besag et al. (1991). According to this specification, the spatial random effects $v_{i}$ are distributed as:

$$
v_{i} \mid v_{j}, \tau_{v} \sim N\left(\frac{1}{\mathrm{n}_{i}} \sum_{i \sim j} v_{j}, \frac{1}{\tau_{v} \mathrm{n}_{i}}\right) \quad i \neq j
$$


where, $j$ refers to the indices of all wards which are neighbours of a given ward $i$, and $\mathrm{n}_{i}$ is the total number of neighbours of ward $i$. To determine the number of neighbours and to identify the pairs of wards as neighbours, a contiguous neighbor-adjacency matrix was created using the poly2nb function in the spdep R package (Bivand et al., 2011). To define neighbours, we used queen adjacency method according to which two wards are neighbours if they share a common boundary or a point.

The above specification implies that spatial component of error at any ward $\left(v_{i}\right)$ has a normal distribution. That distribution is centered around the mean of the spatial error components of all its neighbouring wards and the variation around the mean is inversely proportional to the number of its neighbours. As the number of neighbouring wards increase, the spread of the distribution around the mean value also reduces.

Similar to $\log \left(\tau_{\delta}\right), \log \left(\tau_{v}\right)$ is also assigned a prior of log-gamma distribution with mean and precision of 1 and 0.0005 . The parameters describing the priors are often referred to as hyper-parameters, which in the current specifications are $\tau_{\delta}$ and $\tau_{v}$, for uncorrelated and spatially correlated error terms, respectively. Their respective distributions are called hyperprior distributions. Fixed effects, on the other hand, have no hyperparameters. Note that all the priors are defined with very large variances (inverse of variance varies from 0 for intercept, to 0.0005 for hyperparameters, to 0.001 for other fixed effects), and therefore, these priors are uninformative, signifying lack of our prior understanding of these effects.

Note that while $\tau_{\delta}$ is an indicator of uncorrelated heterogeneity across all wards, $\tau_{v}$ represents the variation of the conditional autoregressive specification, therefore the two cannot be interpreted in the similar manner. Using R-INLA output, we obtained the posterior distributions of spatial error components of each of the ward. To estimate variance of spatial components, we simulated 1000 random values of spatial components of each of the ward using their corresponding posterior distributions. For each of those 1000 runs, we estimated variance of spatial error across all wards, and the mean of 1000 variance values was estimated as the variance of spatial error component.

To compare the performance of Bayesian models, Deviance information criterion (DIC) is estimated which is a Bayesian version of Akaike information criterion (AIC). DIC is calculated as:

$$
D I C=D\left(\hat{\theta}_{\text {Bayes }}\right)+2 p_{D I C}
$$

where, the first term in right-hand side is the deviance calculated for the posterior mean of the estimated parameters, and second term is the effective number of parameters in the model. Compared to maximum likelihood method, in Bayesian hierarchical modeling, deviance is evaluated at mean of posterior distributions rather than maximum likelihood estimate of parameters and the number of effective parameters tend to be less (Gelman et al., 2014, p. 172). Similar to AIC, lower value of DIC implies higher predictive accuracy.

293 Before progressing to development of the regression model, we investigate the Pearson correlation 294 between various variables in order to avoid multicollinearity between the independent variables. VKT has 
high positive correlation with number of bus stops and high negative correlation with population density. Population density and number of bus stops are also highly negatively correlated. We found that adding the three variables together did not significantly affect the standard deviations of their coefficients compared to when they are added individually. In addition, magnitude of the coefficients also changed by a maximum of $25 \%$ in case of population density. At the same time, DIC reduced significantly by 5 units compared to the model with only VKT among the three variables. Therefore, in the final model, all the three variables were retained.

Table 2: Results of intercept-only and full model using Bayesian Hierarchical modelling

\begin{tabular}{|c|c|c|c|c|c|c|}
\hline \multirow[b]{2}{*}{ Variable } & \multicolumn{3}{|c|}{ Intercept-only model } & \multicolumn{3}{|l|}{ Full model } \\
\hline & mean (sd) & $\mathbf{P}_{2.5}$ & $P_{97.5}$ & mean (sd) & $\mathbf{P}_{2.5}$ & $P_{97.5}$ \\
\hline Intercept & $-10.108(0.042)$ & -10.192 & -10.024 & $-8.049(1.480)$ & -10.988 & -5.170 \\
\hline$\%$ Literate & & & & $-0.024(0.009)$ & -0.042 & -0.006 \\
\hline$\%$ Main workers & & & & $0.039(0.016)$ & 0.008 & 0.071 \\
\hline In(Population density) & & & & $-0.355(0.090)$ & -0.532 & -0.177 \\
\hline $\ln (\mathrm{VKT})$ & & & & $0.317(0.064)$ & 0.192 & 0.445 \\
\hline \# Bus stops & & & & $0.012(0.004)$ & 0.004 & 0.021 \\
\hline \# Flyovers & & & & $0.137(0.056)$ & 0.028 & 0.247 \\
\hline \# Roundabouts & & & & $-0.042(0.038)$ & -0.117 & 0.034 \\
\hline$\tau_{\delta}$ (iid component) & $3.069(1.103)$ & 1.503 & 5.772 & $3.434(0.651)$ & 2.304 & 4.85 \\
\hline$\tau_{v}$ (spatial component) & $0.467(0.136)$ & 0.251 & 0.779 & $9.706(11.461)$ & 1.548 & 38.67 \\
\hline DIC & 1737.91 & & & 1705.71 & & \\
\hline
\end{tabular}



Figure 1: Relative risk of VRU fatality risk in wards across Delhi

\section{Results}

We obtained results for an intercept-only as well as a full model, as shown in Table 2. The table shows mean and $2.5^{\text {th }}$ and $97.5^{\text {th }}$ percentiles of the posterior distributions of all coefficients as well as error components, and also presented are the DIC values. The percentiles represent the $95 \%$ confidence 
component, while the rest is due to unstructured heterogeneity of ward. Full model explained $89 \%$ of the variation of spatial error, however, it explained less than $20 \%$ of the variation in uncorrelated heterogeneity. In the intercept-only model, exponential of intercept term, $\exp \left(\beta_{0}\right)$, represents the background fatality risk across the wards and exponential of sum of two error components, $\exp \left(\delta_{i}+v_{i}\right)$, represents the relative risk of each ward, and the latter is presented in Figure1.

On the basis of $95 \% \mathrm{Cl}$ of posterior distributions, all the coefficients are significantly different from zero, except number of roundabouts. Percentage of literate population, number of roundabouts and population density have a negative association with fatality risk and percentage of population as workers, number of bus stops, number of flyovers, and VKT have positive association. Here, a positive association indicates that with an increase in a variable, the fatality risk increases.

\section{Discussion}

\subsection{Socio-economics and demographics}

An increase in literacy rate, which is an indicator of socio-economic status (SES) of the ward, is associated with lower risk of fatalities. This is possible because population with low SES are more likely to be VRUs as they walk, cycle, use PT or ride MTW for their daily travel. In Delhi, only one-fifth of all households own a car (Census-India, 2012). With low level of car ownership, whether an individual is VRU or not is highly sensitive to their income level. Million Death Study (Hsiao et al., 2013) also reported pedestrian deaths to be positively associated with living in poorer neighborhoods. A large number of studies have shown similar results linking higher risk of fatalities, or number of road crashes in general, with lower SES (Aguero-Valverde and Jovanis, 2006; Wier et al., 2009; DiMaggio et al., 2015; Xu et al., 2017).

The percentage of population as main workers is positively associated with the fatality risk. According to Census 2011, 65\% of the main workers in Delhi are in the age group 30-59, and 86\% of them are males. Therefore, workers represent a specific demographic group, which is predominantly male in the age group 30-59. This is also reflected in the age and sex distribution of injuries. For the three-year fatality data (2010-2012) reported in the current study, sex of victims was reported for year 2010, according to which males accounted for $91 \%$ of all fatality victims, while their share in overall population is $54 \%$ (CensusIndia, 2012). The disproportionate share of men in the age group 15-59 years was also reported by the Million Death Study (Hsiao et al., 2013). This explains a positive association of main workers with fatality risk.

It is interesting to note that even though Pearson correlation between percentage of main workers and percentage of literate population is positive, the coefficients of the two variables are opposite in signs. This means that SES (indicated by literacy) and demographics (indicated by workers) have their independent effects which are opposite in directions.

\subsection{Traffic volume and roundabouts}

Positive effect of VKT is expected and has been consistently reported by all studies which considered it as one of the covariates (Amoh-Gyimah et al., 2016; Demiroluk and Ozbay, 2014; DiMaggio et al., 2015; Quddus, 2008; Xu et al., 2017; Aguero-Valverde and Jovanis, 2006; Huang et al., 2010; Wier et al., 2009). According to the posterior distribution of coefficient of number of roundabouts, up to $85^{\text {th }}$ percentile 
value is a negative. One of the benefits of Bayesian method over frequentist method is that while the latter reports coefficients as single values, the former reports them as distributions of values. Thus it can be said that, given the data, there is more evidence in favour of a negative association of roundabouts with fatality risk than a positive or no effect.

The negative association of roundabouts with fatality risk is also expected from international experience. Roundabouts have been adopted globally as a traffic calming measure because of their effectiveness to reduce road crashes. According to a meta-analysis of 28 studies in non-US locations, conversion of intersections to roundabouts resulted in $50-70 \%$ reduction of the fatal crashes (Elvik, 2003). In Holland, before-and-after studies of the construction of about 200 roundabouts showed a significant drop of $89 \%$ of pedestrian fatalities (Schoon and Van Minnen, 1994).

\subsection{Flyovers and bus stops}

Apart from roundabouts, flyovers and bus stops are two other variables representing road infrastructure, and we will discuss the two together because of their related features. Flyovers have a strong positive association with fatality risk, with one flyover increasing the relative risk by $15 \%$ compared to no flyover. Bus stops are also positively related to fatality risk. These effects are independent of the volume of traffic. The coefficients of the two variables may not be isolated effects of the two infrastructure elements and could also be indicating the effect of other built environment features which occur simultaneously.

Flyovers in Delhi have been built along major arterial roads (for instance the two ring roads) as well as highways. Bus stops in Delhi are also located on most major roads, of which arterials and highways are subsets. Most residential and commercial areas do not have enough carriageway width for movement of the bus. Therefore, both bus stops and flyovers are likely to represent road types with heavy vehicular movement. The roads with flyovers also have 40 to $50 \%$ higher average speed than other major roads (Mohan et al., 2017).

A study conducted in Delhi (Khatoon et al., 2013) studied traffic characteristics before and after the replacement of signalised junction with a flyover. The study reported that the average speed travelled by trucks and buses as well as the variability of the speed of all vehicle types increased after the construction of flyover. Another study from Delhi also found presence of flyovers as a significant factor affecting the number of pedestrian crashes (Rankavat and Tiwari, 2015). Thus there is a strong evidence suggesting that construction of flyovers results in high increase in the risk of injuries.

One of the major confounding variables which has been excluded in this analysis is the volume of trucks, which may bring endogeneity in the model results. A network of national highways pass through the city in multiple directions making it a natural route for long-distance trucks as well as a hub for goods exchange. A large proportion of goods movement occurs in Delhi through road-based freight modes. High volume of trucks is also a major source of pollution in Delhi (Goel and Guttikunda, 2015). It is possible that the model may have introduced an upward bias in the effect of number of flyovers and number of bus stops. However, given the magnitude of association for both bus stops and flyovers as well as high statistical significance indicated by their posterior distributions, the addition of any other risk factor is unlikely to change the direction of association. 


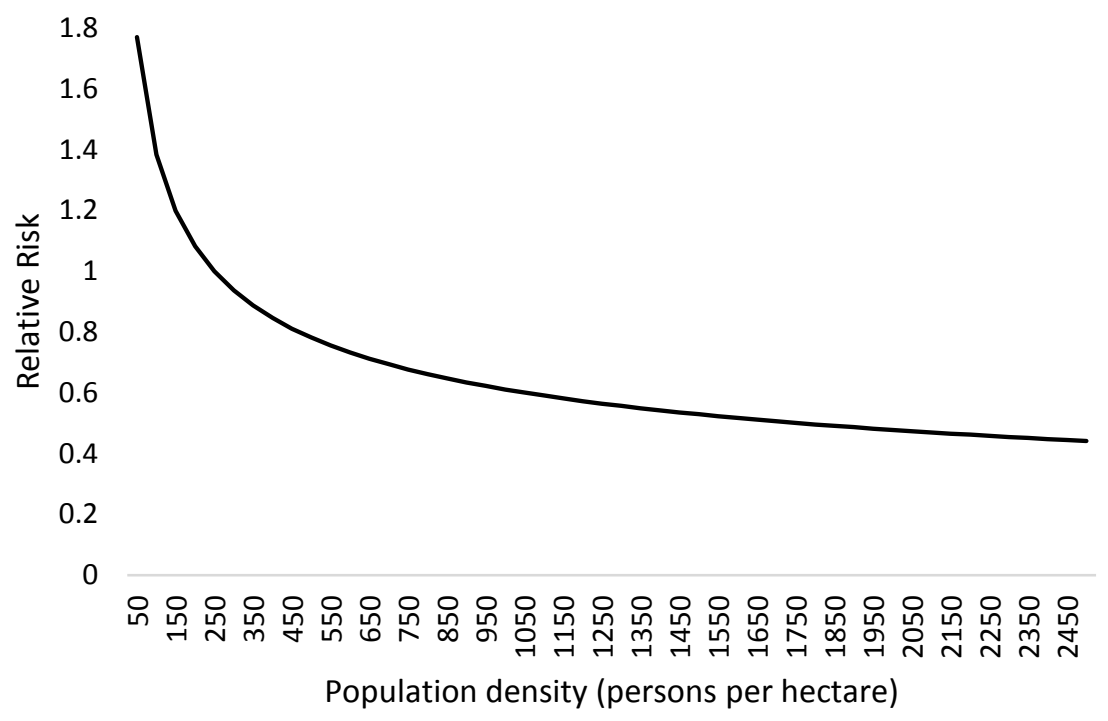

Figure 2: Relative risk at different density levels compared to city-level average (250 pph)

\subsection{Population density}

Population density is log transformed therefore its coefficient cannot be interpreted in the similar manner as other independent variables. Since the relative risk is an exponent of product of the variable and its coefficient $\left(\exp \left(\beta_{i} \mathrm{X}_{i}\right)\right)$, the relative risk (RR) of population density can be expressed as power functions, as ${ }^{1}$ :

In order to understand the effect of density, we expressed the relative risk with respect to the overall average population density (total population/total built-up area) of $250 \mathrm{pph}$. Figure 2 indicates that relative risk of fatalities is more than 1.8 times higher at density of $50 \mathrm{pph}$ compared to city-level average. The non-linear curve shows that at higher density levels, the effect of density flattens off and the most reduction in relative risk is up to a density of $850 \mathrm{pph}$. There are various factors which could result in this association of density with risk and we discuss those in the following text.

High density locations are more likely to have higher number of pedestrians. In the absence of dedicated facilities for pedestrians and cyclists, the two slow-moving road users occupy the curb-side lane of the roads. This effectively slows down the traffic and makes roads safer. With an increase in the volume of pedestrian, their risk reduces, and this phenomenon is referred to as safety-in-numbers (Jacobsen, 2003; Elvik and Bjørnskau, 2015). Thus the negative association of relative risk with density may likely be an indicator of safety-in-numbers.

High density also attracts higher number of IPT, such as cycle rickshaws, auto rickshaws, and e-rickshaws. These modes are demand responsive and are operated by private operators. Therefore, their volumes are proportional to density or the demand. Since buses do not operate through streets in residential areas, IPT is also used for last-mile connectivity of a bus or metro trip (Goel and Tiwari, 2015). In the absence of

${ }^{1} e^{\beta \cdot \ln (X)}=X^{\beta}$ 
dedicated parking bays or stops, these vehicles idle along the curb-side lane for passenger boarding and alighting, leading to further congestion. On-street parking/idling effectively narrows the roads, and driver tend to be more cautious while driving through those sections (Gattis, 2000).

415 In Delhi, as well as in most Indian cities, most informal neighborhoods or commercial areas have high 416 built-up density and narrow roads. Informality implies that most growth in built-up is in-situ (as opposed 417 to Greenfield development). Also, the street design is not according to municipal bye-laws which ensure 418 wide-enough streets. Formally designed high-income neighborhoods often have wider streets, but due to on-street car parking by the residents, road widths are effectively reduced.

As a result, most through movement of motorised traffic occurs on major roads, and those driving through the narrow streets tend to drive slow. In addition to slower and low volume of traffic, trucks and buses are almost absent in these locations. While trucks are restricted by police, buses do not ply due to lack of space. This can also be seen through a negative correlation of population density with both, number of bus stops as well as VKT, which in turn are proxies of major roads. Therefore, high density should also be interpreted as a proxy of residential/commercial land-use and street design, and these correlates of high density act as speed calming measures.

The relationship of crash risk with population density has been inconsistent across the studies. While density and crash risk, Lovegrove and Sayed (2006), Huang et al. (2010), Dumbaugh and Li (2010), Chakravarty et al. (2010), Siddiqui et al. (2012), and Narayanmoorthy et al. (2013) reported a positive association between the two. Both the studies showing negative relationship were based on country-wide analysis in the UK using wards as areal units, and all the studies showing positive relationship were based in either US or Canada - Florida, San Antonio, California, Manhattan, and Vancouver.

The cities in the US have higher car ownership and lower population density than the UK (Guiliano and Narayan, 2003). Compared to both US and UK, Delhi's density is an order of magnitude higher and car ownership a magnitude of order lower. In a setting with high car ownership, higher density may imply higher number of cars against a smaller number of pedestrians. In contrast, in a setting such as Delhi, it implies much higher number of pedestrians in conflict with comparatively smaller number of motorised modes. Thus, density can imply different mechanisms in place in different settings.

\section{Conclusion}

Pedestrians, cyclists and MTW users constitute the largest group of fatality victims in Delhi. In Delhi as well as in most Indian cities, overall traffic enforcement is weak, especially in terms of speed as well as alcohol limit. In addition, the infrastructure facilities for pedestrians are poor, for cyclists almost absent, and MTW use the same lanes as other motorised modes. The mixing of VRUs with vehicles of much larger weight and speed results in greater injury risk. In this context, improving safety through design of built environment can prove to be highly effective. Therefore, it is important to understand built environment factors which affect fatality risk. In this study we assessed the risk resulting from roundabouts, bus stops, flyovers and population density while controlling for traffic volumes and population characteristics. 
With higher emphasis on smooth traffic flow and higher speed, a large number of flyovers have been built within populated areas in Delhi as well as many Indian cities. We found that an addition of a flyover increases the fatality risk in a ward by up to $15 \%$, and this effect is independent of traffic volume. While the construction of flyovers pose a challenge of lock-in, their effect on speed of vehicles can be controlled by using speed enforcement by the police or using passive measures such as installment of rumble strips. Given the high risk posed by addition of flyovers, their use as congestion mitigation measures within urban areas should be discontinued.

In addition, cities in India need to consider the use of roundabouts as an alternative of traffic junctions to minimise the number of road crashes. Many cities in India are doing exactly the reverse by replacing roundabouts with traffic junctions. For traffic planners to willingly adopt roundabouts, it is important that their designs are based on latest international experience which result in increased safety as well as efficient traffic movement.

There is a positive association with fatality risk and social deprivation, thus indicating socio-economic inequity of injury risk. Given a negative relationship of risk and population density, future studies should investigate the street design and built environment features of high density locations in Delhi to understand the causal mechanism behind this relationship. These factors can then be incorporated in future city designs.

\section{References}

Aarts, L., \& Van Schagen, I. (2006). Driving speed and the risk of road crashes: A review. Accident Analysis Accident Analysis \& Prevention, 38(3), 618-625. doi: http://dx.doi.org/10.1016/j.aap.2005.12.006

Amoh-Gyimah, R., Saberi, M., \& Sarvi, M. (2016). Macroscopic modeling of pedestrian and bicycle crashes: A cross-comparison of estimation methods. Accident Analysis \& Prevention, 93, 147-159. doi: http://dx.doi.org/10.1016/j.aap.2016.05.001

Arora, A., Gadepalli, R., Sharawat, P., Vaid, A., \& Keshri, A. (2014). Low-carbon Comprehensive Mobility Plan: Vishakhapatnam. UNEP DTU Partnership, Technical University of Denmark.

Besag, J., York, J., \& Mollié, A. (1991). Bayesian image restoration, with two applications in spatial statistics. Annals of the Institute of Statistical Mathematics, 43(1), 1-20. doi: 10.1007/bf00116466

Bivand, R. S., Gómez-Rubio, V., \& Rue, H. (2014). Some Spatial Statistical Extensions to R-INLA. Journal of Statistical Software.

Cameron, M. H., \& Elvik, R. (2010). Nilsson's Power Model connecting speed and road trauma: Applicability by road type and alternative models for urban roads. Accident Analysis \& Prevention, 42(6), 1908-1915. doi: http://dx.doi.org/10.1016/j.aap.2010.05.012

Census-India (2012). Census of India, 2011. The Government of India, New Delhi, India.

Census-India (2016). B-28 'Other Workers' By Distance From Residence To Place Of Work And Mode Of Travel To Place Of Work - 2011(India/States/UTs/District), Census of India 2011, The Government of India, New Delhi, India. Accessed online < http://www.censusindia.gov.in/2011census/population_enumeration.html> 
Chakravarthy, B., Anderson, C. L., Ludlow, J., Lotfipour, S., \& Vaca, F. E. (2010). The relationship of pedestrian injuries to socioeconomic characteristics in a large Southern California County. Traffic injury prevention, 11(5), 508-513.

Cramb, S. M., Mengersen, K. L., \& Baade, P. D. (2011). Developing the atlas of cancer in Queensland: methodological issues. International journal of health geographics, 10(1), 1.

Demiroluk, S., \& Ozbay, K. (2014). Spatial Analysis of County Level Crash Risk in New Jersey Using SeverityBased Hierarchical Bayesian Models. Paper presented at the Transportation Research Board 93rd Annual Meeting.

DiMaggio, C. (2015). Small-Area Spatiotemporal Analysis of Pedestrian and Bicyclist Injuries in New York City. Epidemiology, 26(2), 247-254.

Dumbaugh, E., Li, W., \& Joh, K. (2013). The built environment and the incidence of pedestrian and cyclist crashes. Urban Design International, 18(3), 217-228.

EEA (2003). Indicator fact sheet- TERM 200232 EU-Size and composition of the vehicle fleet. European Environment Agency.

Elvik, R. (2003). Effects on road safety of converting intersections to roundabouts: review of evidence from non-US studies. Transportation Research Record: Journal of the Transportation Research Board(1847), 1-10.

Elvik, R. (2009). The non-linearity of risk and the promotion of environmentally sustainable transport. Accident Analysis \& Prevention, 41(4), 849-855.

Elvik, R., \& Bjørnskau, T. (2017). Safety-in-numbers: a systematic review and meta-analysis of evidence. Safety Science, 92, 274-282.

Ewing, R., \& Dumbaugh, E. (2009). The built environment and traffic safety a review of empirical evidence. Journal of Planning Literature, 23(4), 347-367.

Fitzpatrick, K., Carlson, P., Brewer, M., \& Wooldridge, M. (2001). Design factors that affect driver speed on suburban streets. Transportation Research Record: Journal of the Transportation Research Board(1751), 18-25.

Garg, N., \& Hyder, A. A. (2006). Review Article: Road traffic injuries in India: A review of the literature. Scandinavian Journal of Public Health, 34(1), 100-109.

Gelman, A., Carlin, J. B., Stern, H. S., \& Rubin, D. B. (2014). Bayesian data analysis (Vol. 2): Chapman \& Hall/CRC Boca Raton, FL, USA.

Giuliano, G., \& Narayan, D. (2003). Another look at travel patterns and urban form: the US and Great Britain. Urban studies, 40(11), 2295-2312.

Goel, R. (2017). Public health effects of urban transport in Delhi (Doctoral Dissertation). Transportation Research and Injury Prevention Programme, Indian Institute of Technology Delhi, New Delhi.

Goel, R., \& Guttikunda, S. K. (2015). Evolution of on-road vehicle exhaust emissions in Delhi. Atmospheric Environment, 105, 78-90.

Goel, R., \& Tiwari, G. (2016). Access-egress and other travel characteristics of metro users in Delhi and its satellite cities. IATSS Research, 39(2), 164-172.

Goel, R., Guttikunda, S. K., Mohan, D., \& Tiwari, G. (2015). Benchmarking vehicle and passenger travel characteristics in Delhi for on-road emissions analysis. Travel Behaviour and Society, 2(2), 88-101.

Gower, L.A. (2013). 2011 Census Analysis - Method of Travel to Work in England and Wales Report. Analysis and Dissemination, Office for National Statistics, UK.

Graham, D. J., \& Glaister, S. (2003). Spatial variation in road pedestrian casualties: the role of urban scale, density and land-use mix. Urban studies, 40(8), 1591-1607.

Grundy, C., Steinbach, R., Edwards, P., Green, J., Armstrong, B., \& Wilkinson, P. (2009). Effect of $20 \mathrm{mph}$ traffic speed zones on road injuries in London, 1986-2006: controlled interrupted time series analysis. BMJ, 339. 
Accepted for publication in Accident Analysis and Prevention (2017)

Gupta, U., Tiwari, G., Chatterjee, N., \& Fazio, J. (2010). Case study of pedestrian risk behavior and survival analysis. Journal of the Eastern Asia Society for Transportation Studies, 8, 2123-2139.

Gururaj, G. (2008). Road traffic deaths, injuries and disabilities in India: Current scenario. The national medical journal of India, Volume 21.

Guttikunda, S. K., Goel, R., \& Pant, P. (2014). Nature of air pollution, emission sources, and management in the Indian cities. Atmospheric Environment, 95, 501-510. doi: http://dx.doi.org/10.1016/j.atmosenv.2014.07.006

Hadayeghi, A., Shalaby, A., \& Persaud, B. (2003). Macrolevel accident prediction models for evaluating safety of urban transportation systems. Transportation Research Record: Journal of the Transportation Research Board(1840), 87-95.

Hsiao, M., Malhotra, A., Thakur, J. S., Sheth, J. K., Nathens, A. B., Dhingra, N., . . Collaborators, f. t. M. D. S. (2013). Road traffic injury mortality and its mechanisms in India: nationally representative mortality survey of 1.1 million homes. BMJ Open, 3(8). doi: 10.1136/bmjopen-2013-002621

Huang, H., Abdel-Aty, M., \& Darwiche, A. (2010). County-level crash risk analysis in Florida: Bayesian spatial modeling. Transportation Research Record: Journal of the Transportation Research Board(2148), 27-37.

Hydén, C., \& Várhelyi, A. (2000). The effects on safety, time consumption and environment of large scale use of roundabouts in an urban area: a case study. Accident Analysis \& Prevention, 32(1), 11-23.

lamsterdam (2014). Facts \& Figures: Road Safety 2012-2015. Accessed October 10, 2015 from < https://www.amsterdam.nl/parkeren-verkeer/fiets/cycling-amsterdam/road-safety/>

Jacobsen, P. L. (2003). Safety in numbers: more walkers and bicyclists, safer walking and bicycling. Injury prevention, 9(3), 205-209.

Jones, A. P., Haynes, R., Kennedy, V., Harvey, I. M., Jewell, T., \& Lea, D. (2008). Geographical variations in mortality and morbidity from road traffic accidents in England and Wales. Health \& Place, 14(3), 519-535. doi: http://dx.doi.org/10.1016/j.healthplace.2007.10.001

Khatoon, M., Tiwari, G., \& Chatterjee, N. (2013). Impact of grade separator on pedestrian risk taking behavior. Accident Analysis \& Prevention, 50, 861-870. doi: http://dx.doi.org/10.1016/j.aap.2012.07.011

Kim, K., Brunner, I., \& Yamashita, E. (2006). Influence of Land Use, Population, Employment, and Economic Activity on Accidents. Transportation Research Record: Journal of the Transportation Research Board, 1953, 56-64. doi: 10.3141/1953-07

Ladron de Guevara, F., Washington, S., \& Oh, J. (2004). Forecasting crashes at the planning level: simultaneous negative binomial crash model applied in Tucson, Arizona. Transportation Research Record: Journal of the Transportation Research Board(1897), 191-199.

LaScala, E. A., Gerber, D., \& Gruenewald, P. J. (2000). Demographic and environmental correlates of pedestrian injury collisions: a spatial analysis. Accident Analysis \& Prevention, 32(5), 651-658. doi: http://dx.doi.org/10.1016/S0001-4575(99)00100-1

Leden, L. (2002). Pedestrian risk decrease with pedestrian flow. A case study based on data from signalized intersections in Hamilton, Ontario. Accident Analysis \& Prevention, 34(4), 457-464.

Lovegrove, G. R., \& Sayed, T. (2006). Macro-level collision prediction models for evaluating neighbourhood traffic safety. Canadian Journal of Civil Engineering, 33(5), 609-621. doi: 10.1139/I06-013

MacNab, Y. C. (2004). Bayesian spatial and ecological models for small-area accident and injury analysis. Accident Analysis \& Prevention, 36(6), 1019-1028. doi: http://dx.doi.org/10.1016/j.aap.2002.05.001

McKenzie, B., \& Rapino, M. (2011). Commuting in the united states: 2009: US Department of Commerce, Economics and Statistics Administration, US Census Bureau Washington, DC.

Miller, E., \& Ibrahim, A. (1998). Urban form and vehicular travel: some empirical findings. Transportation Research Record: Journal of the Transportation Research Board(1617), 18-27. 
Mohan, D., Tiwari, G., \& Bhalla, K. (2015). Road Safety in India- Status Report. New Delhi: Transportation Research and Injury Prevention Programme, Indian Institute of Technology Delhi.

Mohan, D., Tiwari, G., \& Mukherjee, S. (2016). Urban traffic safety assessment: A case study of six Indian cities. IATSS Research, 39(2), 95-101. doi: http://dx.doi.org/10.1016/j.iatssr.2016.02.001

Mohan, D., Tiwari, G., Goel, R., \& Lakhar, P. (2017). Evaluation of the Odd-Even Day Traffic Restriction Experiments in Delhi, India. Transportation Research Record: Journal of the Transportation Research Board. No. 17-04218

Mohan, D., Tsimhoni, O., Sivak, M., \& Flannagan, M. J. (2009). Road safety in India: challenges and opportunities. University of Michigan, US.

MoRTH (2012). Road Transport Year Book (2011-12). Transport Research Wing, Ministry of Road Transport and Highways, Government of India, New Delhi

MOT (2009). Cycling in the Netherlands. Ministry of Transport, Public Works and Water Management, Directorate-General for Passenger Transport, The Netherlands.

Narayanamoorthy, S., Paleti, R., \& Bhat, C. R. (2013). On accommodating spatial dependence in bicycle and pedestrian injury counts by severity level. Transportation Research Part B: Methodological, 55, 245-264. doi: http://dx.doi.org/10.1016/j.trb.2013.07.004

NCRB (2015). Accidental deaths \& suicides in India 2014. National Crime Records Bureau, New Delhi.

Nilsson, G., 1981. The effects of speed limits on traffic accidents in Sweden. In:Proceedings, International symposium on the effects of speed limits on traffic crashes and fuel consumption, Dublin. OECD, Paris.

Noland, R. B., \& Quddus, M. A. (2004). A spatially disaggregate analysis of road casualties in England. Accident Analysis \& Prevention, 36(6), 973-984. doi: http://dx.doi.org/10.1016/j.aap.2003.11.001

NYDMV (2014). Summary of New York City motor vehicle crashes 2014. New York State Department of Motor Vehicles, New York City, US.

OECD/ECMT (2006). Speed management- Summary Document. Transportation Research Centre. Organization for Economic Cooperation and Development and European Conference of Ministers of Transport.

Peden, M., Scurfield, R., Sleet, D., Mohan, D., Hyder, A. A., Jarawan, E., \& Mathers, C. D. (2004). World report on road traffic injury prevention: World Health Organization Geneva.

Ponnaluri, R. V. (2012). Modeling road traffic fatalities in India: Smeed's law, time invariance and regional specificity. IATSS Research, 36(1), 75-82. doi: http://dx.doi.org/10.1016/j.iatssr.2012.05.001

Pucher, J., Peng, Z. r., Mittal, N., Zhu, Y., \& Korattyswaroopam, N. (2007). Urban transport trends and policies in China and India: impacts of rapid economic growth. Transport Reviews, 27(4), 379-410.

Pulugurtha, S. S., Duddu, V. R., \& Kotagiri, Y. (2013). Traffic analysis zone level crash estimation models based on land use characteristics. Accident Analysis \& Prevention, 50, 678-687.

Quddus, M. A. (2008). Modelling area-wide count outcomes with spatial correlation and heterogeneity: An analysis of London crash data. Accident Analysis \& Prevention, 40(4), 1486-1497. doi: http://dx.doi.org/10.1016/j.aap.2008.03.009

Rankavat, S., \& Tiwari, G. (2015). Association Between Built Environment and Pedestrian Fatal Crash Risk in Delhi, India. Transportation Research Record: Journal of the Transportation Research Board(2519), 61-66.

RITES (2008). Transport Demand Forecast Study and Development of an Integrated Road cum Multi-modal Public Transport Network for NCT of Delhi, Household Interview Survey Report, Chapter-4, Travel Characteristics, RITES Ltd.

RITES (2013). Total Transport System System Study on Traffic Flows and Modal Costs (Highways, Railways, Airways and Coastal Shipping), A Study Report for the Planning Commission, The Government of India, New Delhi, India (2013) 
Rivara, F. P. (1990). Child pedestrian injuries in the United States. Current status of the problem, potential interventions, and future research needs. Am J Dis Child, 144(6), 692-696.

Rouphail, N. M. (1984). Midblock crosswalks: a user compliance and preference study.

Rue, H., Martino, S., \& Lindgren, F. (2009). INLA: Functions which allow to perform a full Bayesian analysis of structured (geo-) additive models using Integrated Nested Laplace Approximaxion. R Package version 0.0 ed.

Schoon, C., \& van Minnen, J. (1994). Safety of roundabouts in The Netherlands. Traffic engineering and control, 35(3), 142-148.

Siddiqui, C., Abdel-Aty, M., \& Choi, K. (2012). Macroscopic spatial analysis of pedestrian and bicycle crashes. Accident Analysis \& Prevention, 45, 382-391. doi: http://dx.doi.org/10.1016/j.aap.2011.08.003

Tanaboriboon, Y., \& Jing, Q. (1994). Chinese pedestrians and their walking characteristics: case study in Beijing. Transportation research record, 16-16.

TFL (2014). Casualties in Greater London during 2013. Fact sheet, Surface Planning, Surface Transport, Transport for London, London, UK.

Tiwari, G. (2002). Planning for bicycles and other non motorised modes: The critical element in city transport system. Paper presented at the ADB International Workshop on Transport Planning, Demand Management and Air Quality.

Tiwari, G., Bangdiwala, S., Saraswat, A., \& Gaurav, S. (2007). Survival analysis: Pedestrian risk exposure at signalized intersections. Transportation research part F: traffic psychology and behaviour, 10(2), 7789.

Török, Á. (2011). Investigation of road environment effects on choice of urban and interurban driving speed. International Journal for Traffic and Transport Engineering, 1(1), 1-9.

USCB (2011). Commuting in the United States: 2009, American Community Survey Reports. US Department of Commerce, Economics and Statistics Administration, US Census Bureau, US.

USDOT (2015). Table 1-11: Number of U.S. Aircraft, Vehicles, Vessels, and Other Conveyances. Bureau of Transportation Statistics, United States Department of Transportation. Accessed onlined $<$ https://www.rita.dot.gov/bts/sites/rita.dot.gov.bts/files/publications/national_transportation_s tatistics/html/table_01_11.html>

Wang, X., Yang, J., Lee, C., Ji, Z., \& You, S. (2016). Macro-level safety analysis of pedestrian crashes in Shanghai, China. Accident Analysis \& Prevention, 96, 12-21. doi: http://dx.doi.org/10.1016/j.aap.2016.07.028

WHO (2015). Global status report on road safety 2015. World Health Organization.

Wier, M., Weintraub, J., Humphreys, E. H., Seto, E., \& Bhatia, R. (2009). An area-level model of vehiclepedestrian injury collisions with implications for land use and transportation planning. Accident Analysis \& Prevention, 41(1), 137-145.

Xu, P., Huang, H., Dong, N., \& Wong, S. C. (2017). Revisiting crash spatial heterogeneity: A Bayesian spatially varying coefficients approach. Accident Analysis \& Prevention, 98, 330-337. doi: http://dx.doi.org/10.1016/j.aap.2016.10.015 